\title{
Offering CF carrier screening: Who set the goal, and what is the goal?
}

In 1989, when the gene for cystic fibrosis (CF) and the delta F508 mutation were identified, it was clear to many of us that there would be considerable controversy about whether to offer screening to detect CF carriers and how to screen. Since that time, many hundreds of different mutations in the CFTR gene have been reported, and a substantial amount of research has evaluated the complex issues associated with CF carrier screening. Along the way, these developments have prompted commentaries on this subject and statements by professional organizations. As yet, the professional organizations with the greatest interest in this issue, the American College of Medical Genetics (ACMG) and the American College of Obstetricians and Gynecologists (ACOG), have not recommended offering CF carrier screening in the reproductive health care setting except to couples with a family history of CF and to reproductive partners of individuals with CF. The article, "Issues in Implementing Prenatal Screening for Cystic Fibrosis: Results of a Working Conference" by Haddow and colleagues, ${ }^{2}$ in this issue of Genetics in Medicine, should be considered in the context of this decade-long process of discovery and debate. This report of the Sixth Scarborough Conference does not conclude the discussion. An initiative to develop a plan for the implementation of CF carrier screening has been established by the ACMG, the ACOG, and the National Institutes of Health. The outcome of that process is an important missing piece of the puzzle.

As background, an NIH Consensus Development Conference held in April of 1997 recommended that: "Genetic testing for CF should be offered to adults with a positive family history of CF, to partners of people with CF, to couples currently planning a pregnancy, and to couples seeking prenatal

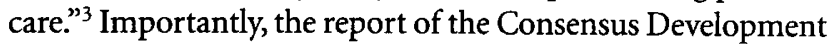
Conference concluded with the statement that it is "essential that offering of CF carrier testing be phased in over a period of time in order to ensure that adequate education and appropriate genetic testing and counseling services are available to all persons being tested." After the Consensus Development Conference report was issued, the ACMG and the ACOG reaffirmed their previous positions on CF carrier screening.

In October of 1997, an NIH Workshop was convened to consider implementation of the Consensus Development Conference recommendations. A commentary on the discussions that occurred at that Workshop has recently been published. ${ }^{4}$ Like the Consensus Development Conference report and the article by Haddow et al., ${ }^{2}$ the report of the Workshop touches on many of the difficult issues associated with offering CF carrier screening. Among these are the wide range of severity of
$\mathrm{CF}$, the differences in carrier frequency and sensitivity of testing in various racial and ethnic groups, the imperfect prediction of the phenotype from the genotype, and the lack of preparation of reproductive health care professionals for implementation of this screening. The most important conclusions of the Workshop were the recommendations regarding the next steps and a timeline for completing these steps. The participants agreed that the next steps should include: the development of protocols or practice guidelines for offering CF screening; the development of educational programs and materials for providers and consumers regarding genetic testing for CF, as well as prototype informed consent protocols and documents; and the further development of laboratory standards. It was further agreed that the relevant professional organizations should be involved in accomplishing these tasks and that, at a minimum, it would be 18 to 36 months before they might be accomplished. Finally, it was agreed that the issue of offering CF screening as the standard of care could only be addressed after these next steps have been accomplished.

Shortly after the NIH Workshop reached these conclusions, the ACMG and ACOG, along with NIH convened a joint Steering Committee to begin work on the recommendations of the Workshop participants. Embarking on genetic screening of the complexity and the potential magnitude of screening proposed for CF is unprecedented, and all of the participants are aware of the serious nature of this task. In particular, those involved believe that success in developing a plan for offering CF screening may be used as a model for implementing other genetic screening in the reproductive health care setting and that failure, were it to occur, would likely be held forth as an example that could negatively impact development and implementation of other genetic tests. After deliberation, the Steering Committee established working groups with broad representation from experts in the field, professional organizations, and other constituencies to address each of the three areas identified by the NIH Workshop. The Steering Committee and three working groups have cross-representation and have worked diligently during the past 15 months. The Steering Committee serves to coordinate the tasks of the working groups and to keep the respective professional organizations informed of the progress. Substantial progress has been made, and the timeline proposed at the NIH Workshop is still within reach. However, success should not be measured by finalizing a plan within the timeline specified, but by proposing an approach and supporting materials that will achieve the goal of screening as defined by the Consensus Development Conference when they made their recommendations. 
In considering where the report of the Sixth Scarborough Conference fits in this process, I think we should pause and reflect on the goal of offering CF screening. Like most of the readers, I did not attend the Consensus Development Conference in April of 1997. In preparation for my role as CoChair of the NIH Workshop that followed, I wanted to understand what the Consensus Development Conference defined as the goal of CF screening and how this led to their recommendations. I listened to many hours of taped presentations and discussions from the Consensus Development Conference. In these discussions, it was observed that when CF carrier screening is offered appropriately and nondirectively during early pregnancy, some fully informed couples without a family history of CF will opt for screening. Furthermore, screening can be successfully performed in these couples, and the couples value and use the information that they gain. This observation was the most compelling argument for the recommendation to offer the screening rather than simply continue to make it available. The Consensus Development Conference report succinctly restated this as: "The goal of genetic testing is to provide individuals with information that will permit them to make informed decisions." This goal is consistent with clinical genetic practice in the United States, and it was embraced by the participants at the Workshop.

The Sixth Scarborough Conference was convened by the Foundation for Blood Research. Not unexpectedly, many of the people who participated in the NIH Consensus Conference or the NIH Workshop, are also participating in the process convened by the ACMG, the ACOG and the NIH. Some, but not all of these people, attended the Sixth Scarborough Conference, and new participants were also brought into the discussion. There was proportionately more representation from the United Kingdom and from industry with interest in CF testing than at the other conferences. A very important disclaimer notes that the report does not reflect the opinions of the 24 different institutions or organizations with which the authors are affiliated. Given the differences in representation and the nature and complexity of the issues, it is also reasonable to assume that although there may have been a majority consensus on some of the discussion points, there was not unanimous agreement on every recommendation by all of the participants or even all 32 authors.
In contrast to the goal of $\mathrm{CF}$ screening developed by the Consensus Development Conference, the stated aim of prenatal screening for cystic fibrosis in the report of the Sixth Scarborough Conference is the "detection of affected fetuses." In reading the sixth Scarborough Conference report, it is apparent that this important difference in the goal of screening, i.e. to detect affected fetuses rather than providing information for informed decision making, impacted the recommendations regarding to whom screening should be offered and the models of screening that should be used. Because the initiative sponsored by the ACMG, the ACOG, and NIH is ongoing, it is not yet possible to know which recommendations currently in development by the professional organizations will agree with those in the Sixth Scarborough conference report. Perhaps the most striking differences in the recommendations could arise from the difference in the goal of screening for CF. In spite of this, the initiative to convene and report on yet another meeting on this important subject should be commended. The continued dialogue by a large number of experts and stake-holders enabled by the Sixth Scarborough Conference is useful. The report helped me to refocus on the goal of genetic screening as the major determinant of the plan for implementation.

Michael T. Mennuti, MD
Professor and Chair
Department of Obstetrics and Gynecology
University of Pennsylvania Medical Center

\section{References}

1. Love $\mathrm{CB}$, Thomson EJ (compilers). Genetic testing for cystic fibrosis. Current bibliographies in medicine, No. 97-2. Bethesda, Maryland: National Library of Medicine, 1997.

2. Haddow JE, Bradley LA, Palomaki GE, Doherty RA, Bernhardt BA, Brock DJH, Cheuvront B, Cunningham GC, Donnenfeld AE, Erickson JL, Erlich HA, Ferrie RM, FitzSimmons SC, Greene MF, Grody WW, Haddow PK, Holmes LB, Howell RR, Katz M, Klinger KW, Kloza EM, LeFevre ML, Little S, Loeben G, McGovern M, Pyeritz RE, Rowley PT, Saiki RK, Short MP, Wald NK, Wilker NL, Witt DR. Issues in implementing prenatal screening for cystic fibrosis: Results of a working conference. Genetics in Medicine 1(4):129-135, 1999.

3. Genetic testing for cystic fibrosis. NIH consensus statement 1997;Apr 14-16;15(4):1-37.

4. Mennuti MT, Thomson E, Press N. Screening for cystic fibrosis carrier state. Obstet Gynecol 1999;93:456-61. 